\title{
O mestre, uma disciplina e o mundo que se revela em bolotas e varetas
}

Edja Trigueiro. (1) Universidade Federal do Rio Grande do Norte, Programa de Pós-Graduação em Arquitetura e Urbanismo, Natal, Rio Grande do Norte, Brasil.

Repetindo Frederico de Holanda em seu escrito sobre Bill Hillier para esta Revista, também estou entre os privilegiados que conheceram Bill décadas atrás. Também escrevo sob o peso da perda que me faz mais uma vez órfã, para afirmar o quão importante foi esse encontro na minha vida e na de muitos aprendizes a minha volta, narrando, ao correr das memórias, as que ficaram mais fortemente gravadas em coração e mente.

\section{Epifania}

O pensamento de Bill Hillier, Julienne Hanson e seus colaboradores iniciais mudou meu modo de ver o mundo, redefiniu minha carreira acadêmica, motivou a criação do grupo de pesquisa em Morfologia e Usos da Arquitetura - MUsA/UFRN (que reúne, desde 2001, morfólogos e aspirantes a) e tem sido a principal moldura conceitual para a construção e direcionamento de estudos sobre temas diversos, produzidos por levas e levas de alunos de graduação e pósgraduação na Universidade Federal do Rio Grande do Norte, e em parcerias acadêmicas com outras instituições, sobretudo a Universidade Federal da Paraíba. Acredito firmemente que as ideias de Hillier, refinadas ao longo do tempo, e ampliadas por contribuições advindas de visões complementares, permanecerão conosco e com os que virão depois de nós, enquanto a sociedade humana for configurada no (e pelo) espaço.

Cheguei a elas por buscar desvendar nexos socioculturais embutidos em arranjos espaciais da arquitetura doméstica brasileira. Dediquei alguns anos a decifrar a arquitetura eclética, movida pela constatação do contínuo desaparecimento de edifícios de aparência pós-colonial e pré-modernista nas ruas do Recife, sem que nada se pesquisasse ou publicasse sobre os bens perdidos, ou sequer fossem referidos nas disciplinas de história do Curso de Arquitetura da Universidade Federal de Pernambuco UFPE, onde decorreu minha graduação. Dos cerca de 10 anos de pesquisa e observação empírica pelas ruas do Recife, ao longo de uma Especialização em Sociologia e um Mestrado em História, ambos também na
UFPE, emergiram mais de 1700 registros, na grande maioria de residências, liames entre as formas de herança colonial e moderna. Faltavam, entretanto, ferramentas de análise morfológica para deslindar os vazios, expondo, quiçá, vínculos entre a forma dos espaços internos e práticas sociais que acompanharam as mudanças nos volumes continentes dessa arquitetura construída ao longo de quase cem anos. O tomar ciência da existência de uma teoria da Lógica Social do Espaço (Hillier \& Hanson, 1984) trouxe a esperança de explorar a alma sociocultural da arquitetura - que Bruno Zevi (1948) e Evaldo Coutinho (1977) me tinham convencido ser o espaço - buscando seus nexos no próprio artefato e não em instrumentos teóricometodológicos de outros campos disciplinares, como por alguns anos eu vinha penando para fazer.

Quis a sorte que fosse aprovado, com bolsa plena pelo Conselho Nacional de Desenvolvimento Científico e Tecnológico $\mathrm{CNPq}$, meu projeto de pesquisa doutoral para realização de tese, entre 1990 e 1994, no University College London, Bartlett School of Graduate Studies, sob orientação de Bill Hillier. Empenhei-me em investigar arranjos de espaços domésticos projetados de meados do século 19 aos anos 1930, no Recife e na Grã-Bretanha, buscando indícios de aproximação entre nexos espaciais de moradias recifenses e britânicas, capazes de reforçar a ideia de que a presença britânica na cena urbana do Recife teria contribuído para alterar modos de vida, como sugeriram estudiosos sobre a preeminência inglesa no Brasil - notadamente Freyre (1948) e Manchester (1933).

Os quase quatro anos de convívio foram, como seria de esperar, de constante aprendizado científico, cujo cerne está exemplarmente narrado no texto de Frederico de Holanda, único dentre os publicados nesta Revista que li antes de concluir este escrito. Foram, também, de aprendizado não menos marcante de outras naturezas, circunscritas, talvez, a qualidades "fenotípicas" do mestre, orientador, revelador de visões. 
Como exemplo da argúcia de visão na guia do meu trabalho, cito sua observação sobre a relevância - que não me tinha parecido digna de nota - de existirem apenas seis pares de estruturas espaciais idênticas em uma coleção de 500 plantas baixas de casas britânicas ${ }^{1}$ que embasaram minha investigação sobre arranjos de espaços domésticos britânicos. A propósito, aponta:
Mesmo se isolássemos os problemas das relações espaciais e de formato e tamanho, mediante, por exemplo, a análise de plantas através de grafos, ainda assim encontramos uma variedade cornucópia e não uma tipologia simples. Por exemplo, um estudo recente de mais de 500 casas vernáculas construídas entre 1843 e 1930 revela exatamente seis pares de grafos duplicados, mesmo tendo sido a amostra recolhida de um único país durante um período em que alguma continuidade tipológica era de se esperar. Plantas parecem ser individuais, frequentemente com parentescos de família ou configurações locais comuns, mas raramente consistentes ou claras o suficiente a ponto de sugerir uma divisão simples em tipos. ${ }^{2}$

Da natureza do guia-guru, alçador de aprendizes a pares, forjador de orientadores, sobejam episódios protagonizados por Bill já à altura da nossa convivência, promovido à categoria de Professor, topo da carreira universitária, e considerado uma das estrelas da Bartlett, esse celeiro de famosos da academia. Dentre o que considero atitudes facilitadoras da vida dos orientandos, cito: as caminhadas que guiava pessoalmente através da City, em qualquer situação meteorológica - e em Londres não faltam rigor e diversidade nelas - explicando, ao vivo, cores e muito gasto de joelho e sapato, as medidas de conectividade, integração, visibilidade e seus efeitos; o empenho em reduzir entraves burocráticos, não apenas os do UCL, como a documentação para a qualificação de projetos de doutorado, mas os de fora da universidade - cartas facilitadoras de pesquisas (i.e. acervo especial da British Library), mediação junto ao temido Home Office para obtenção de vistos (a atuação de Bill Hillier foi crucial para que se concedesse o do meu marido). Cito, ainda, atitudes não ortodoxas que reduziam distâncias hierárquicas: a de aceitar orientar trabalhos em circunstâncias informais, como o da revisão final de minha tese, feita por telefone, eu em uma cabine pública na High Street de Woolwich Arsenal - saco de moedas, lápis e papeis na mão -, ele em Brasília, na sala de Frederico de Holanda, na UnB, enfrentando o que chamou de "pergaminhos do mar morto", quilométricos rolos de papel de fax; a disposição em comparecer a confraternizações de alunos, situando-se na fronteira entre comedimento e informalidade ao interromper as perenes discussões teóricas, com alguma expressão cotidiana chula, como a que serviu, aos brados, de apresentação ao meu marido recém-chegado em festa oferecida por uma mestranda: "Você deve ser o marido de Edja. Eu sou Bill Hillier e NÃO sou um filho da $\mathrm{p}^{*}$. Muito prazer!"3

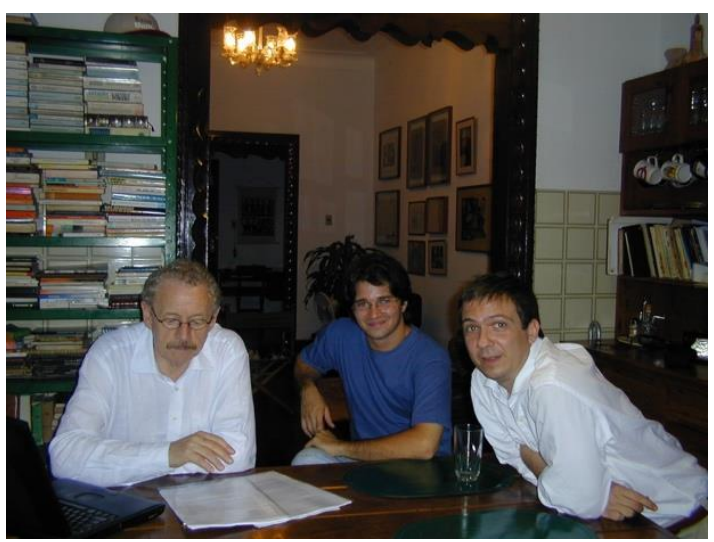

Figura 1. Revisando a palestra em minha casa: Bill Hillier, Cristiano Borba e Luiz Amorim (fotografia: autora).

Anos depois, em 2003, aceitando interromper seu retorno à Inglaterra após compromissos de trabalho em Santiago do Chile, para proferir palestra de abertura do ano letivo em nosso Programa de Pós-graduação em Arquitetura e Urbanismo - PPGAU/UFRN, reavivou em minha memória essa multiplicidade de saberes e ensinamentos, não só nos brindando com uma longa, cristalina e bem estruturada palestra, mas indagando, apontando, observando aspectos que poucos enxergam no meio urbano real, em áreas centrais e periféricas que insistiu em percorrer, de carro e a pé. 


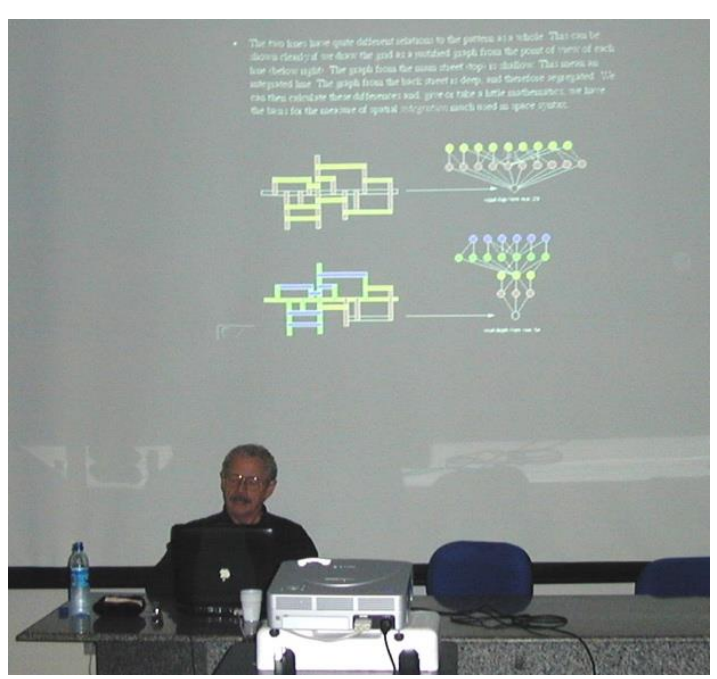

Figura 2. Palestra na UFRN (fotografia: autora).

Além de Natal, visitou a cidade seridoense (parte do sertão potiguar) de Acari, em companhia de sua mulher Sheila, ambos interessados em conhecer cenários do sertão nordestino, como os que tinham visto no filme "Central do Brasil", assistido em Londres, alguns anos antes.

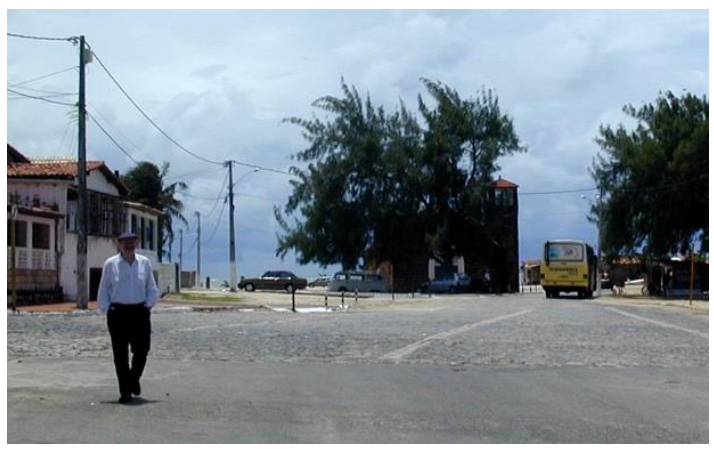

Figura 3. Observando a configuração da Redinha, praia urbana na margem norte do rio Potengi, Natal (fotografia: autora).

Replicaram-se nessa curta estadia o acúmen científico e a deliciosa agudeza de espírito, muito britânica, muito Bill Hillier, sobre o que há em redor. Perambulamos - por sugestão dele - madrugada adentro, por ruas quase desertas em cuja malha orgânica do núcleo original de ocupação ele ia apontando semelhanças com vilarejos europeus - os anéis de permeabilidade ou beady rings estudados em The Social Logic of Space. Isso após um jantar memorável no rustiquíssimo restaurante de nossa amiga Angelina e seu marido francês, na penumbra de uma palhoça iluminada por candeeiro, sob o céu estrelado da caatinga, à beira do açude Gargalheiras. Sobre o jantar ele nos disse, em tom que reputo mais cavalheiresco que exato: "Vocês me levaram para o meio do nada e tive a melhor refeição na América do Sul"4. (Sorry, Fred).

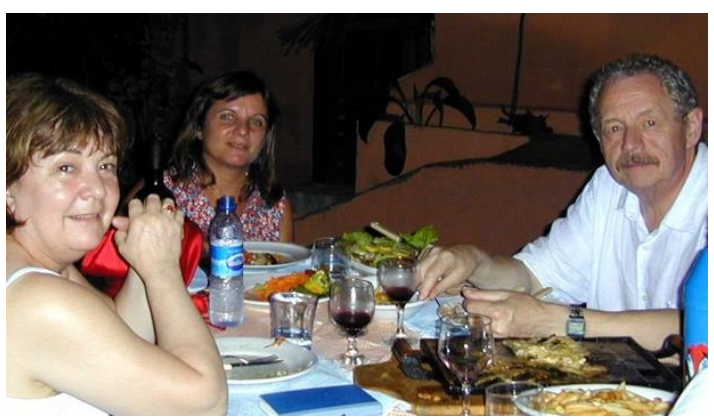

Figura 4. Bistrô às margens do açude Gargalheiras, Acari, Seridó norte-riograndense (fotografia: arquivo da autora).

\section{Multiplicando olhares}

De volta ao University College London em 2004-5, principalmente para buscar atualizar o escopo metodológico da Sintaxe do Espaço em face das novas demandas e diversidade de enfoques perseguidos por nossos alunos, tive oportunidade de participar do programa VivaCity2020, pesquisa multidisciplinar envolvendo cinco universidades ${ }^{5}$ e financiada pela comunidade europeia que contemplou questões de sustentabilidade urbana através de uma nova compreensão do processo de tomada de decisão no desenho urbano. Debito, novamente, à generosidade de Bill Hillier, minha aceitação na qualidade de Honorary Senior Research Fellow, status que isentava as altas taxas cobradas pelo UCL, mesmo para estágios pós-doutorais, não financiadas por nossos órgãos de fomento. Com bolsa da Coordenação de Aperfeiçoamento de Pessoal de Nível Superior-CAPES, e sob tutoria de Hanson, acompanhei, por onze meses, o desenvolvimento de três subprojetos específicos do VivaCity2020 - coordenados por Julienne Hanson, Alan Penn e Bill Hillier, que dialogavam com o que vínhamos investigando na $\mathrm{UFRN}^{6}$ e que me forneceram munição metodológica para abrir o leque de estudos empíricos em atividades de orientação, de volta ao Brasil.

Somaram-se ao aprendizado da participação no VivaCity2020, minha colaboração com o Space Syntax Ltd - empresa de consultoria, projeto e planejamento ancorados na análise sintática do espaço - no projeto Safe \& Easy Movement in Stockwell, coordenado por Alain Chiaradia, que visava contribuir para o estabelecimento de rotas seguras entre moradias e amenidades locais na área 
administrativa de Stockwell, sul de Londres, a partir do entendimento de aspectos físicos facilitadores e inibidores de movimento, permanência e convívio em espaços abertos de conjuntos habitacionais.

Em dias especiais esse e muitos outros projetos, alguns desenvolvidos simultaneamente nos âmbitos acadêmico do UCL e empresarial do Space Syntax Ltd, eram apresentados e discutidos coletivamente. Nesses dias era quase certa a participação de Bill, questionando lacunas, apontando caminhos, detectando - de imediato - achados relevantes, não raro celebrados com uma taça de vinho.

Saudade muita, falta idem. Da continuidade de suas ideias brilhantes como tantas que vêm iluminando estudos nos vários continentes há quase meio século. Como consolo o vingar das sementes plantadas pelas ideias para fazer avançar o conhecimento sobre espaços e pessoas e, oxalá, contribuir para um mundo melhor.

Como testemunho dessas vingas que vêm alicerçando, neste nosso pedaço de mundo, um robusto corpo de pesquisas gravitando em redor da lógica social que a sintaxe do espaço expressa e amolda, agrupo a maior parte do que temos produzido a partir, principalmente da contribuição de Bill Hillier, Julienne Hanson e colaboradores em três categorias: (1) efeitos da estrutura viária sobre a formação e obsolescência de centralidades e edifícios - quanto ao uso, conservação, transformação, desaparecimento e substituição; (2) efeitos potenciais de determinados arranjos de vazios e cheios em facilitar ou dificultar o ir, vir e estar nos espaços abertos, o encontrar-se ou esquivarse do outro; e (3) padrões reveladores de como cheios e vazios internos a edifícios são estruturados para unir ou apartar - e hierarquizar - atividades e pessoas, expressando e conformando modos de habitá-los, em especial no âmbito da moradia.

\section{Efeitos da estrutura viária sobre centralidades e edifícios}

A investigação de possíveis efeitos exercidos pela estrutura viária (os vazios) sobre a (trans)formação de centralidades e sobre os edifícios (os cheios) foi o marco zero para o entendimento de matizes formais da dinâmica de produção e apropriação da cidade na UFRN, estendendo-se, a partir daí, como abordagem central ou complementar em estudos, tais como: fenômenos contemporâneos singulares ou sinalizadores de novas dinâmicas urbanas que se ancoram na configuração de centralidades, em escala metropolitana, urbana, vicinal ou local; produção e apropriação dos espaços topologicamente mais acessíveis como fator de privilégio socioeconômico; articulação entre grandezas de acessibilidade topológica, padrões de movimento, tipos edilícios e atividades econômicas associadas às escalas global e local em uma área urbana contínua; efeitos de obras de grande porte sobre a configuração espacial e a produção imobiliária em seus entornos; marcas similares impressas na configuração viária de cidades em continentes distintos associadas a processos históricos comuns de formação e transformação dos seus espaços.

\section{Efeitos potenciais de arranjos de vazios e cheios em espaços abertos}

Na interseção dos temas centralidade / produção edilícia e configuração / padrões de movimento, situam-se estudos que associam (e dissociam) relações entre acessibilidade, visibilidade e potencial de facilitar ou dificultar o ir, vir, estar, encontrar-se ou esquivar-se em espaços abertos. São investigações sobre atributos físicos de espaços de uso coletivo - configuração, interfaces, usos do solo - e padrões distintos de animação ou esvaziamento, considerados fatores como a interação entre distintos grupos de usuários, e suas atividades em diversos períodos de tempo. Nestes se incluem reflexões sobre rótulos valorativos, não raro de natureza preconceituosa, atribuídos a lugares de alto potencial de convivência, como praias urbanas nordestinas, ou, inversamente, definidores de determinado etos que privilegia o lugar como destino cobiçado em âmbito nacional e internacional, e, ainda, que favorecem a obtenção de selos de acreditação ambiental. Incluem, também, estudos sobre locais de ocorrência de ações antissociais e do emprego de táticas defensivas em percursos diários como meio de esquivar-se de rotas que provocam medo.

\section{Estruturas espaciais edilícias e usos em edifícios}

O entendimento de relações entre habitação e sociedade impressas no espaço doméstico é, como referi, o tema que me levou à Sintaxe 
do Espaço e permanece privilegiado em nosso grupo de pesquisa, contribuindo para o conhecimento: de moradias vernáculas em áreas rurais e urbanas norte-rio-grandenses que expressam e acomodam modos de morar desde o século 19, e se foram amoldando a novas demandas residenciais; de paralelos entre alterações feitas por moradores de conjuntos habitacionais horizontais e verticais construídos pelo poder público e o espaço das moradias autoconstruídas em que habitavam anteriormente; de filiações estilísticas e critérios de classificação e de valorização em moradias comissionadas e projetadas por profissionais arquitetos para clientes particulares em várias cidades do Nordeste (i.e. Natal, Fortaleza, João Pessoa).

Os três vieses analíticos expostos aqui por vezes confluíram, juntos ou de per si, para subsidiar a avaliação ou o desenvolvimento de projetos, em trabalhos de conclusão de cursos de graduação e como produto parcial para obtenção de título de mestre no Programa de Pós-Graduação em Arquitetura, Projeto e Meio Ambiente - PPAPMA, nosso Mestrado Profissional.

Incluo aqui esse panorama de estudos, certamente incompleto, como testemunho do legado de Hillier e da amplitude de caminhos abertos pela Sintaxe do Espaço, na esperança de que possa suscitar a tessitura ou o fortalecimento de laços entre estudiosos de temas afins, porventura leitores, nestes tempos em que o obscurantismo, a ignorância e o retrocesso da urbanidade parecem tão ameaçadores. Esperançando, também ter contribuído para que não haja dúvida quanto à impropriedade de se considerar a metodologia da Sintaxe do Espaço como "matematização do óbvio" (a propósito, a "colega" citada por Frederico de Holanda, cujo projeto foi refutado sob esta alegação, sou eu).

Profundamente agradecida ao Mestre amado, encerro minha narrativa sobre a felicidade de ter sido discípula e continuadora das ideias de Bill Hillier, trazendo as vozes de alguns dos pesquisadores - os que consegui contatar nos últimos dias - que comigo iniciaram ou continuaram investigações ancoradas na Análise Sintática do Espaço e que vêm carregando e passando adiante o bastão.

\section{Alexandre Augusto Bezerra da Cunha Castro}

Doutorando em Arquitetura e Urbanismo, PPGAU-UFRN

Poucas pessoas causaram impacto e inspiração sobre que profissional eu queria ser como Bill Hillier. Suas contribuições transformaram não somente minha maneira de enxergar e compreender a ciência e a pesquisa, como também o significado da arquitetura, das pessoas e de tudo que compõe o que está ao nosso redor. Enquanto barreiras e permeabilidades tiverem um propósito na nossa sociedade, o espaço sempre será a máquina. Obrigado, Bill.

\section{Ana Paula Campos Gurgel}

Professora, Teoria e História da Arquitetura e Urbanismo, FAU-UnB

Cedo em minha trajetória acadêmica fui encantada por linhas coloridas que, mais do que belas, significavam muito. Os trabalhos do prof. Bill Hillier expandiram minha capacidade crítica e abriram caminhos. Seu legado continuará a transformar perspectivas de pesquisa aqui e além.

\section{Clóvis Dias}

Professor, UFPB

O homem é o seu legado. Quando aprendi de Hillier que lugares não são coisas locais, que é a cidade em seu todo que faz o lugar, compreendi a importância que a construção de uma viazinha nas franjas de uma cidade tinha no todo dessa cidade e nos seus lugares mais diversos. A cidade incessantemente prenhe, adquire continuadamente uma nova forma e a força dessa forma define lugares e centralidades em um processo de descartes e resgates, reconfigurando o espaço urbano. Isso não é pouco como criação intelectual e expressa bem a estatura desse mestre pensador da cidade.

\section{Fabrício Lira Barbosa}

Doutorando em Arquitetura e Urbanismo PPGAU-UFRN. Professor Substituto no curso de graduação em Arquitetura e Urbanismo, UFRN

Hillier possibilitou uma quebra de paradigmas com os quais sempre ousei trabalhar. Há oito anos redescobri e revi conceitos sobre como o espaço arquitetural se relacionava com as pessoas alterando rumos profissionais e acadêmicos. Mais que uma 
escola sobre o pensamento morfológico, a Sintaxe do Espaço nos orienta a perceber e vivenciar a arquitetura como jamais houvera pensado.

\section{Flávia Monaliza Lopes}

Doutoranda em Arquitetura e Urbanismo, UFPB

Estudar a sintaxe auxiliou a entender a forma do espaço como agente ativo, que adentra e amolda a vida cotidiana das pessoas, possibilitando o desenvolvimento de comunidades mais interativas e vivas.

\section{João Batista Carmo}

Professor do Instituto Federal de Educação, Ciência e Tecnologia do Rio Grande do Norte, IFRN

É refutável a afirmação de que para entender o espaço urbano é preciso amá-lo ou, apenas, olhá-lo. Quando amamos alguém ou algo muitas vezes não enxergamos tudo a nossa volta. E olhar não significa enxergar! Para enxergá-lo, necessitamos de lentes matemáticas muito específicas ao passo que o amor ou o olhar podem, por vezes, trair a mais atenta e genuína percepção.

Para ser compreendido, o espaço urbano necessita ser enxergado - tal como o céu de Galileu narrado na peça do dramaturgo alemão Bertolt Brecht, chamada A vida de Galileu - por instrumentos e tecnologias capazes de suscitar análises espaciais desprovidas de paixões, ilusões e ideologias. Na referida obra, Galileu - contestando o saber científico conservador da época clamava para que os sábios olhassem pelo seu telescópio permitindo-lhe compartilhar suas descobertas científicas, pois sob a ótica do velho sistema, Galileu afirmara ser impossível calcular - com precisão - a posição futura das estrelas. Céticos e relutantes, os sábios pediam - em vez de enxergar pelo telescópio - razões: "Razões, Senhor Galileu, razões!".

Pois bem, a Teoria da Lógica Social do espaço em minhas análises espaciais tem sido meu telescópio de Galileu.

\section{Henrique Ramos}

Mestre em Arquitetura e Urbanismo, PPAPMA-UFRN, Escritório Caldas Ramos Arquitetos, Natal/RN

Há cinco anos fui apresentado à teoria criada por Bill Hillier e Julienne Hanson, ao iniciar um mestrado em projeto de arquitetura e meio ambiente. Há cinco anos a Sintaxe Espacial me permitiu melhor entender o real protagonismo do espaço para a experiência das pessoas. Espaço e pessoas, objetos significantes do propósito de existir dos arquitetos. Hillier, com sua revelação em forma de teoria e criação de um novo código para comunicar o que o espaço tem a nos dizer, teve um profundo impacto na minha compreensão do potencial deste mesmo espaço para os encontros (e desencontros) humanos. Impactou, assim, minha prática de fazer arquitetura - ofício a que me dedico cotidianamente, e o qual tento exercer com um olhar atento à academia. Não tive o prazer de conhecer Bill Hillier, mas por meio da sua teoria, de alguma forma, a ele me sinto próximo, e o agradeço por haver me permitido esse 'encontro'. Como não nos sentirmos próximos a quem nos faz ver e enxergar?

\section{José Aureliano de Souza Filho}

Mestre em Arquitetura e Urbanismo PPAPMA/UFRN, Substituto no curso de graduação em Arquitetura e Urbanismo, UFRN

Foi no campo da prática arquitetônica que tive meu encontro com as ideias de Bill Hillier e Julliene Hanson, ao longo do mestrado profissional no PPAPMA/UFRN. Os instrumentos da Sintaxe do Espaço me ofereceram uma possibilidade de avaliação mais consciente das escolhas projetuais, contudo, ainda que possa parecer marginal à valiosa e abrangente contribuição de Hillier para compreensão mais objetiva do espaço e da sua relação com a sociedade, foi sua teorização sobre o projeto de arquitetura que mais iluminou minhas inquietações intelectuais. Num tempo em que nos voltamos a teorizar sobre a atividade projetual, não podemos negligenciar seu pensamento - como o foi na década de 1970 - de que o projeto não pode ser burocratizado e a dimensão cultural lhe é tão própria quanto à arquitetura.

\section{Lucy Donegan}

Professora Adjunta do Departamento de Arquitetura e Urbanismo, UFPB

Bill Hillier teve, com o apoio de muitos outros, a sensibilidade de ver o vazio com formas de unir ou separar pessoas e funções, e de criar modos de representar e analisar, nesse vazio, padrões espaciais relacionados a sociais. Aliado a isso, sua crença no poder 
aglutinador e quase mágico da cidade - "a rua une o que a sociedade dividiu" -, encantou muitos e ajudou a formar uma base que avança, nos quatro cantos do mundo, em entender complexidades sociais que se realizam no espaço. Para mim o ferramental e a perspectiva postos à frente por Hillier proveu meios de apresentar e analisar experiências espaciais (na casa e na cidade) que antes não tinham linguagem para serem compartilhados de modo claro, metodológico, preciso, e sensitivo. Na sua ida fica a certeza de que deixou muito aqui. Com sinceros agradecimentos.

\section{Maryá S. Aldrigue Casado}

Doutora em Teoria e História da Arquitetura e do Urbanismo, IAU-USP São Carlos

Acredito que apesar de lugar-comum, Hillier e Hanson (através de você, Edja) alteraram e ampliaram minha perspectiva de compreensão da arquitetura. Antes tão focada nas relações espaciais e padrões formais e construtivos, e tão afastada das discussões sociais envolvidas. Posso dizer que, ainda que distante (oficialmente) dos estudos sintáticos em minhas pesquisas, não mais consegui analisar as 'casinhas' latinoamericanas sem considerar suas premissas.

\section{Mauricio Martins}

Doutorando em Arquitetura e Urbanismo, PPGAU-UFRN

Após Hillier, os efeitos práticos de maior alcance da arquitetura tornaram-se mais tangíveis. Depois que li Hillier, senti que me tornei arquiteto - não no nível das aparências, mas no nível de como sua nova abordagem reestruturou os espaços da minha vida.

\section{Nicholas Martino}

Doutorando, University of British Columbia

Com Hillier, aprendi que o todo é mais do que a soma das partes. Seu legado vai muito além de reflexões teóricas sobre a essência da arquitetura, fundamenta uma maneira de olhar pro mundo que estará sempre presente na visão daqueles que compreenderam suas ideias.

\section{Rodrigo Nascimento}

Professor do Centro Universitário de João Pessoa, Unipê

A sintaxe espacial - com seus múltiplos resultados nos estudos de Bill Hillier, colaboradores e discípulos - me ajudou a enxergar que é possível a matemática se transformar em uma espécie de poesia da forma social impregnada no lugar. De sua estranheza gráfico-numérica inicial emanam as mais belas interpretações da relação homem-espaço que conferem sentido para a poesia do ser-cidade.

\section{Sílvio Melo Junior}

Mestrando em Arquitetura e Urbanismo, PPGAU-UFRN

As ideias de Hillier e Hanson me auxiliaram a compreender, investigar e principalmente enxergar o espaço a partir da visão do outro, relacionando as dimensões sociais e formais da visibilidade no ambiente construído.

\section{Valéria Ferraz Severini}

\section{Doutora em Arquitetura e Urbanismo, FAU-USP}

Tomando como ponto de partida estudos de sintaxe espacial que indicavam a inserção da Ribeira (um dos bairros do centro histórico de Natal, RN) nos novos limites do centro expandido da cidade, a dissertação de mestrado, denominada "Turismo Cultural na Ribeira: possibilidades e limitações", analisou como essa nova facilidade de acesso poderia ser utilizada em benefício do surgimento de uma infraestrutura de apoio ao desenvolvimento do turismo cultural. Já na tese de doutorado, intitulada "Hospitalidade Urbana nas Grandes Cidades. São Paulo em foco", as ideias de Hillier serviram para a definição de umas das categorias de análise da cidade hospitaleira: a permeabilidade (física). Além de possibilitar um número maior de trajetos entre origem e destino, uma cidade mais permeável pode ajudar na geração de encontros entre moradores e turistas que passarão a usufruir com mais intensidade o espaço urbano.

\section{Valério Augusto Soares de Medeiros}

Arquiteto da Câmara dos Deputados (Brasília/DF) e Professor UnB

A tarde em Londres se mantinha fria - os últimos dias de mês (provavelmente fevereiro: já não me lembro bem) corriam pelas janelas translúcidas do prédio austero, algo burocrático, da Torrington Place. Perdido em meio às pilhas de papéis e livros espalhados sobre sua mesa, o Professor Bill Hillier vasculhava um mapa enquanto conversava comigo. Seu modo peculiar de expressão, movido por uma voz progressivamente baixa, talvez pela idade, 
transmitia uma agudeza hesitante, margeando momentos de loquacidade e silêncio. $\mathrm{O}$ tempo de orientação seria rápido - um encontro curto depois de seu regresso do Japão, onde fizera palestras e prestara consultoria. Eu precisava esclarecer poucas dúvidas.

Entre um assunto e outro, ao finalmente encontrar o mapa e me mostrar, ele apontou, entusiasmado, um conjunto de áreas em Tóquio cujos usos descrevia como comércios, varejo, serviços - era um dos centros da capital. Ao perceber que todas as indicações estavam em japonês, e sequer a legenda eu conseguira compreender, perguntei-lhe se falava a língua. A resposta foi um não, seguida por explicações sobre como, para ler usos, importava também decifrar a forma da cidade. Cada vez mais empolgado, disse-me que a estrutura urbana continha uma mensagem precisa que poderíamos decodificar. Se treinássemos, mesmo com poucas informações, seríamos capazes de "ver" a sociedade naquele emaranhado de ruas e quarteirões aparentemente caótico.

De tudo o que aprendi naquela estada incluindo bons amigos que conheci, a riqueza

\section{Notas}

${ }^{1}$ Compiladas dos dois primeiros periódicos dedicados à construção civil na Inglaterra - The Builder (editado desde 1843) e The Building News (desde 1854), nos quais publicavam profissionais engenheiros, arquitetos, construtores, estudantes (até amadores, em concursos regularmente promovidos pelo The Building News).

${ }^{2}$ No original: "Even if we isolate the problem of spatial relations from that of shape and size by, for example, analysing plans as graphs, then we still find cornucopian variety rather than simple typology. For example, a recent study of over 500 English vernacular houses built between 1843 and 1930 reveals exactly six pairs of duplicate graphs, even though the sample was taken from a single country during a period where some typological continuity could be expected. Plans seem to be individual, often with family resemblances or common local configurations, but rarely

\section{Referências}

Coutinho, E. (1977) O espaço da arquitetura. São Paulo, Perspectiva.

Freyre, G. (1948) Ingleses no Brasil: aspectos da influência britânica sobre a vida, a paisagem e a cultura do Brasil. Rio de Janeiro, José Olympio. das bibliotecas, a vida intensa de uma cidade que ainda acredita ser (ou é?) o centro do universo -, a lição sobre ler a cidade foi simbólica para o meu estágio de doutorado, sob supervisão de Bill Hillier na UCL, no já distante ano de 2006. Além de assistir às suas aulas e da maneira própria de remeter aos estudos prévios, articulando artigos e ideias, lembro-me particularmente da atenção que dava às perguntas que fazíamos, fosse numa orientação ou num encontro informal, pelos corredores da universidade. Mesmo que a resposta não viesse no momento, o que gerava uma certa inquietação, dias depois ele retomaria o assunto, sempre com uma sugestão instigante. A geração dos que tiveram o prazer em conhecê-lo - obrigado, Edja, por me apresentá-lo no primeiro congresso de Sintaxe que participei, em 2001 ! - sentirá particularmente a ausência. O conforto é saber que as ideias que Bill deixou são sólidas o suficiente para permanecerem e se transformarem, florescendo já independentes de si.

consistent enough or clear enough to suggest a simple division into types. HILLIER, Bill. Space is the Machine, Cambridge: Cambridge University Press, 1996, p. 216 (T.A).

${ }^{3}$ Em inglês, se não nos trai a memória: "You must be Edja's husband. I am Bill Hillier and I'm NOT a son of $a b^{*}$. Nice to meet you!".

${ }^{4}$ Em inglês, se não nos trai a memória: "You brought me to the middle of nowhere and I've had the best meal in South America".

${ }^{5}$ Lancaster, Salford, Sheffield, London Metropolitan e UCL.

${ }^{6}$ Work packages (do VivaCity2020) intitulados: Secure Urban Environment by Design, The Generation of Diversity, e A Community Pattern Book for Housing coordenados, respectivamente, pelos Professores Bill Hillier, Alan Penn e Julienne Hanson.

Hillier, B., \& Hanson, J. (1984) The social logic of space. Cambridge, Cambridge University Press.

Zevi, B. (1977) Saber ver a arquitetura. Lisboa, Arcadia. 